\title{
Standing on shoulders
}

\author{
Peter J.F.M. Merkus
}

Affiliation: Dept of Paediatrics, Division of Respiratory Medicine and Allergy, Radboud University Nijmegen Medical Centre, Amalia Children's Hospital, Nijmegen, The Netherlands.

Correspondence: P.J.F.M Merkus, Dept of Paediatrics, Division of Respiratory Medicine and Allergy, Radboud University Nijmegen Medical Centre, PO Box 9101, Nijmegen, 6500 HB, The Netherlands. Email: p.merkusacukz.umen.nl

0 @ERSpublications

It is at the crossroads of different scientific fields that the most interesting studies are created http://ow.ly/q1WXU

If I have seen further it is by standing on the shoulders of giants.

- Isaac Newton

This saying was already a popular metaphor in the middle ages, and still is. A contemporary meaning of this would be: one who discovers by building on discoveries made by predecessors. And in this issue of the European Respiratory Journal, CHANG et al. [1] have done exactly that. Appreciating and using the ideas of a classical physiological study [2], and combining this with the results of modern molecular biology they demonstrate how, at the crossroads of two completely different scientific fields, an added value is created that brings us forward in understanding one of the most fascinating phenomena in respiratory medicine: lung growth and repair.

Obviously, "classical" and anatomical studies have been regularly used to confirm anatomical and pathological concepts, using lung function data to assess growth of lungs and airways in healthy children $[3,4]$, children with asthma [5] or preterm infants [6]. However, the study by CHANG et al. [1] is far more advanced because it introduces new applications of novel infant lung function techniques and incorporates these with classic physiological concepts [2], while combining them with advanced subtyping of progenitor cells.

In children aged 3-28 months, membrane diffusion capacity and capillary blood volume increased with body size, but the membrane resistance to diffusion relative to the total pulmonary resistance to diffusion remained similar with growth. In addition, the authors observed that the ratio of pro-angiogenic to nonangiogenic circulating haematopoietic stem/progenitor cells (CHSPCs) was related to a higher pulmonary diffusion capacity, as well as a higher pulmonary capillary vascular volume [1]

Because alveolar development is highly dependent on the formation of the pulmonary microvasculature, it is crucial for the understanding of lung growth to assess which factors, hormones and cells co-determine pulmonary angiogenesis and vasculogenesis. Probably even more important is that this knowledge may be the key to novel treatments that enhance alveolar formation. These progenitor cells seem to play a most important role here, and this may apply to premature infants [7], children with severe lung disease [8] and, perhaps, also adults [9]. Other findings, such as observations that CHSPCs are increased in menstruating females who exhibit a cyclic increase of diffusing capacity [10], and that infusion of angiogenic cells helps to restore alveolar development in a mouse model of bronchopulmonary dysplasia [11], also strongly suggest that angiogenic cells play a role in developing or restoring the pulmonary vasculature and may enhance alveolar formation indirectly.

In addition, these observations are in line with older studies. A large interindividual variability in the number of alveoli was recognised decades ago [12-14] and one can speculate that this is partly due to biological variation in the numbers and/or ratio of pro- and non-angiogenic CHSPCs. Also the greater

Received: July 182013 | Accepted: Aug 122013

Conflict of interest: None declared.

Copyright (C)ES 2014 
capillary volume found in males compared to females in infancy [1], fits very well with the larger numbers of alveoli found in males compared to females [13, 14].

The research into the possible medical use of stem cells has exploded and was the reason to honour top researchers with the Nobel prize [15]. Although it will take many years before novel treatment modalities are proven safe and effective, progress is being made and, even for a complex organ such as the lung, the prospects look good. It seems plausible then that the "classical old fashion physiology" will remain necessary to assess the functional benefits of such highly advanced treatment modalities of the 21 st century.

\section{References}

1 Chang DV, Tiller CJ, Kisling JA, et al. Membrane and capillary components of lung diffusion and pro-angiogenic cells in infants. Eur Respir J 2014; 43: 497-504.

2 Roughton FJ, Forster RE. Relative importance of diffusion and chemical reaction rates in determining rate of exchange of gases in the human lung, with special reference to true diffusing capacity of pulmonary membrane and volume of blood in the lung capillaries. J Appl Physiol 1957; 11: 290-302.

3 de Jong PA, Long FR, Wong JC, et al. Computed tomographic estimation of lung dimensions throughout the growth period. Eur Respir J 2006; 27: 261-267.

4 de Jong PA, Nakano Y, Lequin MH, et al. Estimation of lung growth using computed tomography. Eur Respir J 2003; 22: 235-238.

5 Merkus PJ, van Pelt W, van Houwelingen JC, et al. Inhaled corticosteroids and growth of airway function in asthmatic children. Eur Respir J 2004; 23: 861-868.

6 Gappa M, Stocks J, Merkus P. Lung growth and development after preterm birth: further evidence. Am J Respir Crit Care Med 2003; 168: 399.

7 Alphonse RS, Rajabali S, Thebaud B. Lung injury in preterm neonates: the role and therapeutic potential of stem cells. Antioxid Redox Signal 2012; 17: 1013-1040.

8 van Haaften T, Thebaud B. Adult bone marrow-derived stem cells for the lung: implications for pediatric lung diseases. Pediatr Res 2006; 59: 94R-99R.

9 Butler JP, Loring SH, Patz S, et al. Evidence for adult lung growth in humans. N Engl J Med 2012; 367: $244-247$.

10 Farha S, Asosingh K, Laskowski D, et al. Pulmonary gas transfer related to markers of angiogenesis during the menstrual cycle. J Appl Physiol 2007; 103: 1789-1795.

11 Balasubramaniam V, Ryan SL, Seedorf GJ, et al. Bone marrow-derived angiogenic cells restore lung alveolar and vascular structure after neonatal hyperoxia in infant mice. Am J Physiol Lung Cell Mol Physiol 2010; 298: L315-L323.

Dunnill MS. The problem of lung growth. Thorax 1982; 37: 561-563.

Thurlbeck WM. Postnatal growth and development of the lung. Am Rev Respir Dis 1975; 111: 803-844.

Thurlbeck WM. Postnatal human lung growth. Thorax 1982; 37: 564-571.

Takahashi K, Yamanaka S. Induction of pluripotent stem cells from mouse embryonic and adult fibroblast cultures by defined factors. Cell 2006; 126: 663-676. 